\title{
Numerical and experimental investigation of alumina-based nanofluid effects on double-pipe heat exchanger thermal performances
}

\author{
A. Bendaraa ${ }^{1}$ (D) My. M. Charafi $^{1} \cdot$ A. Hasnaoui ${ }^{1}$
}

Received: 29 June 2020 / Accepted: 9 January 2021 / Published online: 22 January 2021

(c) The Author(s) 2021 OPEN

\begin{abstract}
In this study, we investigate the thermal behaviour of nanofluids in a double-pipe heat exchanger. It is about a counterflow configuration, designed to cool a lubrication unit of a thermoelectric power plant. The subject of this work is to evaluate the thermal performances of the exchanger by using a nanofluid based on alumina suspension comparing with deionized water. In order to evaluate the thermal performance of the studied configuration, we carried out numerical experiments in an application developed on COMSOL Multiphysics environment, these experiments are utilized to show the feasibility of this application. As result, we found that the nanofluid with an increase in its volume fraction leads to an increase in the overall exchange coefficient, the convective heat transfer coefficient, as well as the efficiency and the power of the exchanger. It is noted that an increase of $1 \%$ in volume fraction, can enhance the overall exchange coefficient, the power and the effectiveness of the exchanger by $17.62 \%, 1.473 \%$ and $10.80 \%$ respectively. Besides, it is noted that the increase in the concentration of nanofluids leads to a narrowing of the pinch points of the inlet and outlet temperatures, which means that nanofluids are more efficient in cooling temperatures than conventional fluids.
\end{abstract}

Keywords Double-pipe heat exchanger - Nanofluids - Alumina - Thermal performances · Heat transfer - Finite element method·COMSOL multiphysics

\begin{tabular}{|c|c|c|c|}
\hline \multirow{2}{*}{\multicolumn{2}{|c|}{ Abbre }} & & \\
\hline & & $C_{p N f}$ & Specific heat of nanofluid $\left(\mathrm{J} / \mathrm{Kg} .{ }^{\circ} \mathrm{C}\right)$. \\
\hline \multicolumn{2}{|c|}{ English variables } & $D_{\text {hlubricant }}$ & Hydraulic diameter lubricant side (m). \\
\hline C & Heat capacity ratio. & & Diameter nanofluid side (m). \\
\hline K & Overall exchange coefficient $\left(\mathrm{W} / \mathrm{m} .{ }^{\circ} \mathrm{C}\right)$. & $D_{\text {lubricant }}$ & Diameter of lubricant section (m). \\
\hline NTU & Number of Transfer Units. & $D_{N f}$ & Diameter of water section $(\mathrm{m})$. \\
\hline$P$ & Power of heat exchanger (W). & $h_{\text {lubricant }}$ & Convection transfer coefficient lubricant side \\
\hline & Prandtl dimensionless number & $h_{N f}$ & Convection transfer coefficient nanofluid side \\
\hline$Q$ & rred $(W)$. & & $\left(\mathrm{W} / \mathrm{m}^{2} .{ }^{\circ} \mathrm{C}\right)$ \\
\hline & Heat transfer area $\left(\mathrm{m}^{2}\right)$. & $k_{B f}$ & Base fluid Thermal conductivity $\left(\mathrm{W} / \mathrm{m} .{ }^{\circ} \mathrm{C}\right)$. \\
\hline & Velocity $(\mathrm{m} / \mathrm{s}$ & $k_{N p}$ & Nanoparticle Thermal conductivity $\left(\mathrm{W} / \mathrm{m} .{ }^{\circ} \mathrm{C}\right)$. \\
\hline & & & Conductivity of the inner tube wall $\left(\mathrm{W} / \mathrm{m} .{ }^{\circ} \mathrm{C}\right)$. \\
\hline \multicolumn{2}{|c|}{ Variables with subscripts } & $k_{\text {lubricant }}$ & Lubricant thermal conductivity $\left(\mathrm{W} / \mathrm{m} .{ }^{\circ} \mathrm{C}\right)$. \\
\hline- & Specific heat of Base fluid $\left(\mathrm{J} / \mathrm{Kg} .{ }^{\circ} \mathrm{C}\right)$. & & Water thermal conductivity $\left(\mathrm{W} / \mathrm{m} .{ }^{\circ} \mathrm{C}\right)$. \\
\hline & Specific heat of nanoparticles $\left(\mathrm{J} / \mathrm{Kg} .{ }^{\circ} \mathrm{C}\right.$ & $\dot{\mathrm{m}}_{\text {lub }}$ & Mass flow of lubricant $(\mathrm{Kg} / \mathrm{s})$. \\
\hline & Specific heat of lubricant $\left(\mathrm{J} / \mathrm{Kg} .{ }^{\circ} \mathrm{C}\right)$. & $\dot{\mathrm{m}}_{\mathrm{Nf}}$ & Mass flow of nanofluid $(\mathrm{Kg} / \mathrm{s})$. \\
\hline
\end{tabular}

A. Bendaraa, anass.bendaraa@gmail.com | 'LS3M, Polydisciplinary Faculty of Khouribga, Univ. Sultan Moulay Slimane, 25000 Khouribga, Morocco. 


$\begin{array}{ll}N_{f} & \text { Nanofluid. } \\ \mathrm{Nu} & \text { Nusselt dimensionless number } \\ q_{t h} & \text { Thermal flow of hot fluid }\left(\mathrm{W} /{ }^{\circ} \mathrm{C}\right) . \\ q_{t c} & \text { Thermal flow of cold fluid }\left(\mathrm{W} /{ }^{\circ} \mathrm{C}\right) . \\ T_{i, l u b r i c a n t} & \text { Inlet temperature of lubricant }\left({ }^{\circ} \mathrm{C}\right) . \\ T_{o, l u b r i c a n t} & \text { Outlet temperature of lubricant }\left({ }^{\circ} \mathrm{C}\right) . \\ T_{i, N f} & \text { Inlet temperature of nanofluid }\left({ }^{\circ} \mathrm{C}\right) . \\ T_{o, N f} & \text { Outlet temperature of nanofluid }\left({ }^{\circ} \mathrm{C}\right) . \\ T_{i, B f} & \text { Inlet temperature of base fluid 'Water }\left({ }^{\circ} \mathrm{C}\right) . \\ T_{o, B f} & \text { Outlet temperature of base fluid ' } \operatorname{Water}^{\prime}\left({ }^{\circ} \mathrm{C}\right.\end{array}$

Greek symbols \& Greek with subscripts

$\rho \quad$ Density $\left(\mathrm{Kg} / \mathrm{m}^{3}\right)$.

$\rho_{B f} \quad$ Density of Base fluid $\left(\mathrm{Kg} / \mathrm{m}^{3}\right)$.

$\rho_{\mathrm{Np}} \quad$ Density of nanoparticles $\left(\mathrm{Kg} / \mathrm{m}^{3}\right)$.

$\phi \quad$ Particle volume fraction (\%).

$\varepsilon \quad$ Effectiveness.

$\mu_{\text {lubricant }}$ Viscosity of lubricant $(\mathrm{Kg} / \mathrm{m} . \mathrm{s})$.

$\mu_{\mathrm{B} f} \quad$ Viscosity of base fluid $(\mathrm{Kg} / \mathrm{m} . \mathrm{s})$.

$\mu_{N f} \quad$ Viscosity of nanofluid $(\mathrm{Kg} / \mathrm{m} . \mathrm{s}$

\section{Introduction}

Heat exchangers are widely used in many industrial applications, for example in the chemical industry, power generation, food industry, environmental engineering, waste heat recovery, air conditioning and refrigeration [1]. In front of energy challenges that the world faces, industrialists are motivated to apply energy-saving methods, by mastering the process of the energy exchange at heat exchangers with all their types. Recent advances in nanotechnology have shown that the addition of nanoparticles in a base fluid, so-called nanofluids, used for the first time by Choi [2], for example, alumina nanoparticles $\left(\mathrm{Al}_{2} \mathrm{O}_{3}\right)$, can significantly increase the heat transfer of nanofluids compared to conventional fluids (deionized water for example). The addition of these nanoparticles can change the thermal properties of the base fluid. These properties become more and more important depending on the type of suspension as well as the type of operating fluid [3]. For this purpose, a wide range of research has focused on the study of this coolant and the role it can play in the improvement of industrial devices such as heat exchangers. Bahiraei et al. conducted several studies and investigations of the use of nanofluids in different heat exchanger configurations, see for example their study of the destruction of the exergy and generation of entropy for the flow of a new nanofluid containing a graphene-silver nanocomposite in a micro-heat exchanger envisaging a viscous dissipation [4] in which they deduced that the generation of friction entropy intensifies with the increase in Reynolds number and concentration and by increasing the Reynolds number, the contribution of the nanofluid side to the destruction of energy increases compared to that of the waterside. Furthermore, the efficiency of the second law decreases with increasing either the Reynolds number or the concentration. this same group of researchers studied complex exchanger configurations, namely spiral heat exchangers, using alumina as a nanofluid [5], for the same configuration they studied the effect of the use of a new biological nanofluid containing functionalised graphene nanoplatelets on the thermal characteristics of this exchanger [6]. Sözen et al. [7, 8] focused on improving heat transfer in plate heat exchangers, carrying out numerical and experimental investigations on the effects of nanofluids on the thermal performance of this type of heat exchanger, in this work the working fluids used are nanofluids based on kaolin and $\mathrm{TiO}_{2}$ deionized water. Bahmani et al. [9] studied the heat transfer and turbulent flow of water/alumina nanofluid in a double-tube heat exchanger in parallel and counterflow. a calculation code based on the FORTRAN language was developed using the singlephase $k-\varepsilon$ model. The results of this study indicated that increasing the volume fraction of nanoparticles or the Reynolds number leads to an increase in the Nusselt number and the convective heat transfer coefficient. The maximum rate of improvement in mean Nusselt number and thermal efficiency is $32.7 \%$ and $30 \%$, respectively. Besides, the increase in the volume fraction of nanoparticles leads to an increase in the fluid outlet temperature and wall temperature. Goodarzi et al. [10] report the results of experiments on the thermal conductivity, specific heat capacity and viscosity of nitrogen-doped graphene nanofluids (NDG), as well as their convective heat transfer behaviour in a double-tube heat exchanger. A calculation code was produced to simulate the transfer by convection in this exchanger. for Reynolds numbers between 5,000 and 15,000 (turbulent flow) and the percentages of the volume fraction of the nanofluids between $0.00 \%$ and $0.06 \%$. An increase in the Reynolds number or the percentage of nanomaterials could perhaps improve the heat transfer of the working fluid. For example, the use of a nanomaterial with a concentration of $0.06 \%$ in the base fluid resulted in a $15.86 \%$ improvement in the convective heat transfer coefficient compared to water. Akbari et al. [11] studied the heat transfer by laminar forced convection of $\mathrm{Al}_{2} \mathrm{O}_{3} /$ water nanofluid nanofluids through a horizontal ribbed microchannel. The central section of the bottom wall of the microchannel was at a lower temperature than that of the inlet fluid. Simulations were carried out for Reynolds numbers 10 and 100 . The results found indicate that normal internal ribs or turbulators can significantly improve convective heat transfer in a microchannel. However, the addition of high ribs can result in a higher friction factor than the corresponding microchannel with a constant rib 
height. The results also show that by increasing the rib height and the volume fraction of the nanoparticles, the coefficient of friction, the heat transfer rate and the average number of ribbed microchannels tend to increase. The field of use of nanofluids in heat exchangers has benefited from a number of reviews that have been the subject of publications, these reviews have shown the dynamism of researchers in the field. Bahiraei et al. [12] reviewed and summarized the state of art in using nanofluids in heat exchangers, including those performed on a flat plate, double tube, tubular and compact heat exchangers. Meanwhile, some fascinating aspects of the combination of nanofluids with heat exchangers are introduced. Omidi et al. [13] have dedicated a study for high concentrations of the double-pipe heat exchanger. This type of heat exchanger has attracted a lot of attention because of its simplicity and wide range of utilization. Kumar et al. [14] reviewed the technology of plate heat exchangers by using nanofluids as coolant, they showed that increasing the volume fraction of nanofluids improves the performance. Huminic et al. [15] have summarized important published guidelines on improving convective heat transfer in heat exchangers using the nanofluids on both sides. The first presents the theoretical and experimental results for thermal conductivity, viscosity and Nusselt number, while the second focuses on the application of nanofluids in various exchangers: plate heat exchangers, tube heat exchangers, heat exchangers compact and double tube heat exchangers. Other recently published work shave highlighted the effect of nanofluids on the thermal performance of heat exchangers. the field of nanofluids is still under development, in recent years several kinds of research have revealed the birth of a new type of nanofluid, namely hybrid nanofluids and therefore a very large number of researchers, for example, Giwa et al. [16] and Gürbüz et al. [17] have incorporated it as working fluid in different heat exchanger configurations in which promising results have been the subject of several publications. Other advances in nanomaterials have led to the birth of Nano-Encapsulated phase-change materials that can improve convective transfer within various geometries Several researchers have tested this material in microchannels $[18,19]$ and have found encouraging results. This study we have focused in particular on improving heat transfer in heat exchangers. The study combines the experimental aspect with numerical simulations, dissecting the influence of the use of nanofluids on the thermal performance of the double-pipe heat exchanger configuration. This type of exchanger is operational in a lubrication system of a thermoelectric power-plant, the internal fluid being considered as a hot fluid (lubricating oil) and the external fluid as a cold fluid (deionized water). The objective of this work is to evaluate the thermal performance of this exchanger by using a nanofluid as a cooling fluid and to see the effect of the addition of nanoparticles on its characteristics. the novelty of our work is the proposal of a more efficient solution and to incorporate it in industry. it is an extrapolation of an existing real case, of which we propose to use nanofluids instead of a conventional fluid. the chosen coolant will be able to increase the performance of all the installation and to envisage an optimal use. Several experiments carried out on this device to derive the experimental data, which were compared with the simulation results studied in the COMSOL Multiphysics platform. The results showed a strong agreement with the experiment which allowed us to validate our simulation model and to provide a solution to increase the performance of this exchanger, this solution lies in the use of nanofluids as cooling fluid with different concentrations. All these points are explained in the document according to the hierarchy below, the following section will, therefore, be dedicated to the explanation of the cooling process by showing the different roles of each piece of equipment in the installation. In the third section, we will characterize the thermophysical properties of $\mathrm{Al}_{2} \mathrm{O}_{3}$ /water nanofluid and estimate its thermal behaviour for different volume fractions of nanoparticles. Then, the simulation procedure, the basic parameters programmed in the COMSOL environment and the study of the adopted mesh will be the subject of the following sections. Finally and before a conclusion that summarizes all the work carried out, a sixth section will be reserved for the discussion of the results found.

\section{Process description and experimental data}

The experimental Kit highlighted in this study is a device for cooling the lubrication loop of a thermoelectric power plant turbine shaft. It is a mechanism that aims to assume the delivery of lubricant at a temperature that tolerates a good operation of the plant. This process uses a counterflow arrangement of the fluids. Its purpose is to keep the lubricant at a tolerable temperature and for good operating conditions, the turbine lubricant enters at a temperature of $360 \mathrm{~K}$ with a flow rate of $0.2 \mathrm{~kg} / \mathrm{s}$; the water passes through the inner tube with a flow rate of $0.1 \mathrm{~kg} / \mathrm{s}$ and its inlet temperature is $300 \mathrm{~K}$. The studied device is a heat exchanger consisting of two concentric tubes $5 \mathrm{~m}$ long with an internal diameter of $10 \mathrm{~cm}$ and an external diameter of $16 \mathrm{~cm}$. Through the two loops, the first is reserved for the lubricant circulation, while the second deals with the circulation of the cooling fluid. This installation is equipped with two centrifugal pumps, which ensure the permanent routing of these two fluids. Figure 1 illustrates 


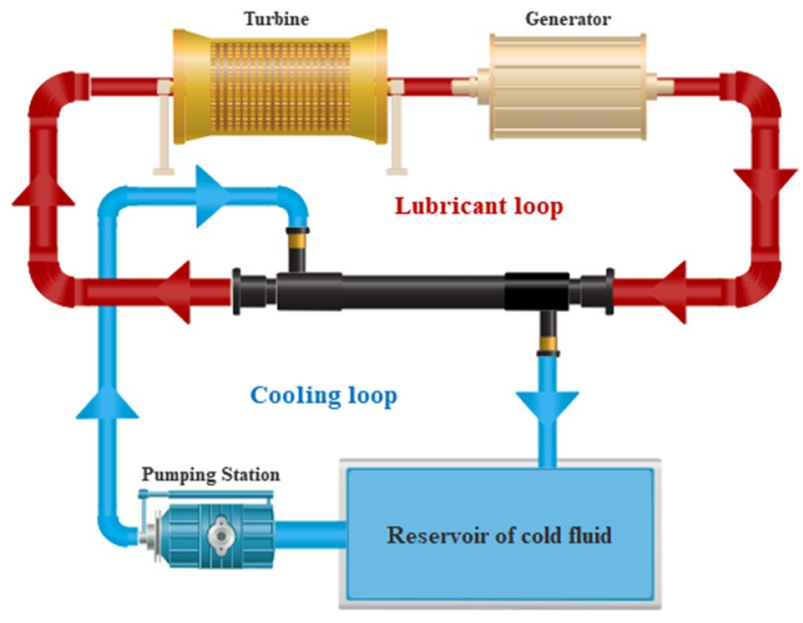

Fig. 1 Constituent parts of the cooling loop

the constituent parts of this experimental kit. In the present study, special attention has been paid to the cooling equipment of the lubricating oil, in which we focused on the primordial organ performing this function, namely a double-pipe heat exchanger (Fig. 2). The latter is the primordial organ of the installation, it uses distilled water to perform the cooling process of the lubricant, so that the flow of the two-fluid occurs counter-flow, while the centre tube houses the lubricating oil and the outer tube houses the water as a cooling fluid.

The operating parameters of the heat exchanger are drawn from the control room of the power plant, these parameters include temperature inputs and outputs of the heat exchanger, efficiency, power and the logarithmic mean temperature difference (LMTD) of this device and this after a follow-up that was spread for five days. The parameters resulting from these tests are then drawn up in Table 1.

\section{Thermophysical properties of nanofluids}

The parameters that characterize the convective heat transfer are a function of many thermophysical properties of the nanofluid. To determine these parameters, the calculation of density, thermal conductivity, specific heat and viscosity, is necessary. For this purpose, we use the models presented in the literature.

The density of the nanofluids can be computed using classical formulas derived for a two-phase mixture. The effective density of the nanofluid is given by $[20,21]$ :

$\rho_{N f}=(1-\Phi) \rho_{B f}+\Phi \rho_{N p}$

The specific heat of the nanofluid is calculated from Pak $\&$ Cho model [22] as follows:

$C p_{N f}=(1-\Phi) C p_{B f}+\Phi C p_{N p}$

For calculating the thermal conductivity of nanofluid, we use the Maxwell Model [23, 24]:

$\frac{k_{N f}}{k_{B f}}=\frac{k_{N p}+2 k_{B f}+2 \Phi\left(k_{N p}-k_{B f}\right)}{k_{N p}+2 k_{B f}-\Phi\left(k_{N p}-k_{B f}\right)}$

And Einstein model [25] to calculate the viscosity:
Fig. 2 Representation of the exchange process

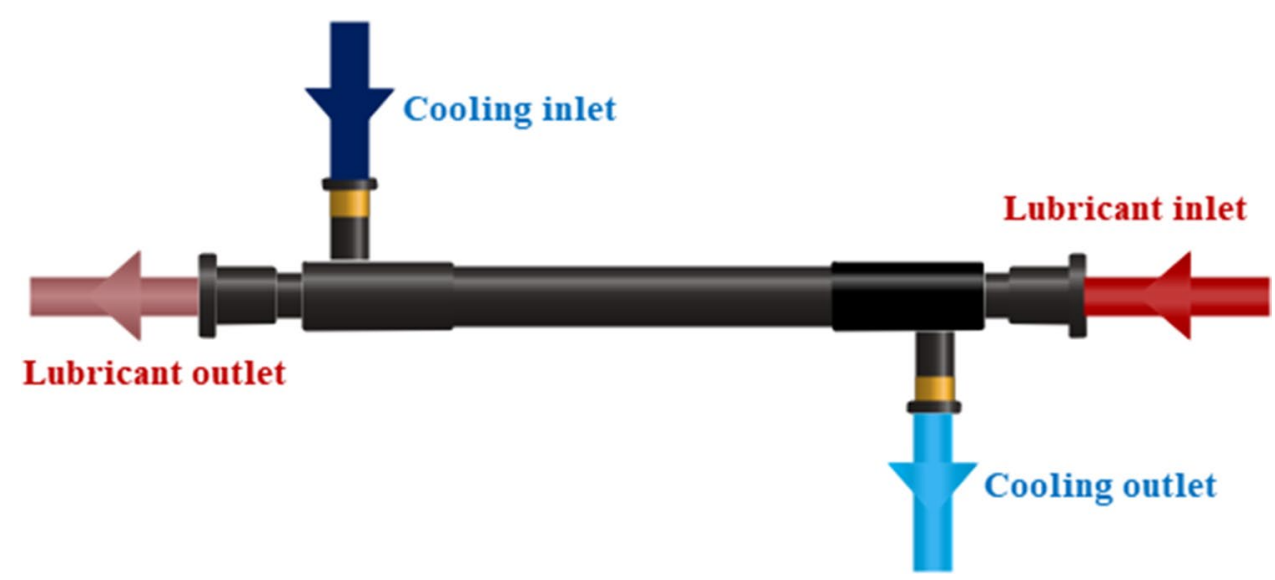

The operating parameters of the heat exchanger

\begin{tabular}{lllllll}
\hline$T_{i, \text { lubricant }}$ & $T_{o, \text { lubricant }}$ & $T_{i, B f}($ Water $)$ & $T_{o, B f}($ Water $)$ & LMTD & Effectiveness & Power \\
\hline $360{ }^{\circ} \mathrm{K}$ & $315^{\circ} \mathrm{K}$ & $300^{\circ} \mathrm{K}$ & $316.7^{\circ} \mathrm{K}$ & $27.67^{\circ} \mathrm{K}$ & 0.42 & $6321(\mathrm{~W})$ \\
\hline
\end{tabular}

Table 1 The operating parameters of our system
SN Applied Sciences

$$
\text { A SPRINGER NATURE journal }
$$


Table 2 Summary of thermophysical properties of fluids \& $\mathrm{Al}_{2} \mathrm{O}_{3}$

\begin{tabular}{lclll}
\hline Thermophysical proprieties & \multicolumn{2}{l}{ Fluids } & Nanoparticles \\
\cline { 2 - 3 } & $\mathrm{B}_{\mathrm{f}}$ (Water) & Lubricant & $\mathrm{Al}_{2} \mathrm{O}_{3}$ \\
\hline $\mathrm{C}_{p}\left(\mathrm{~J} / \mathrm{Kg}^{\circ} \mathrm{C}\right)$ & 4181.8 & 1744 & 761.55 \\
$\rho\left(\mathrm{Kg} / \mathrm{m}^{3}\right)$ & 998.2 & 876 & 3960.14 \\
$\lambda\left(\mathrm{W} / \mathrm{m}^{\circ} \mathrm{C}\right)$ & 0.6 & 0.1103 & 37.17 \\
$\mu * 10^{-3}(\mathrm{Kg} / \mathrm{m} \mathrm{s})$ & 1.002 & 16.7 & - \\
\hline
\end{tabular}

$\mu_{N f}=\mu_{B f}(1+2,5 \Phi)$

Table 2 presents the thermophysical properties of the used fluids as well as the alumina nanoparticles [26, 27].

For applications with a large variation in temperature range, thermophysical parameters have been chosen from several experiments at the laboratory scale, which has been the subject of a large number of recent publications in the field of thermophysical properties characterization. The evolution of these properties as a function of temperature will be the subject of the following.

The density of the base fluid (Water) as a function of temperature is written as [28]:

$\rho_{B f}=-0.0024 T^{2}+0.963 T+1009.8$

Which takes into account the volume extension as temperature increases.

The specific heat of the base fluid is calculated as follows [28]:

$C p_{B f}=4.2483 T+1882.4$

For the thermal conductivity of nanofluid, we use the model bellow [29]:

$\frac{k_{N f}-k_{B f}}{k_{B f}}=0.764 \Phi+0.0187(T+273.15)-0.462$

The model presented in [30] reserved to calculate the viscosity as a function of temperature:

$\mu_{B f}=0.004012-2.107 .10^{-5} T+3.85 .10^{-8} T^{2}-2.3973028410^{-11} T^{3}$

Using these models, it was possible to describe the evolution of the thermophysical properties of aluminabased nanofluids as a function of temperature. Figures. 3,4 and 5 show these evolutions, where we can see that the thermal conductivity increases remarkably by increasing the volume fraction as well as the temperature (Fig. 3). Figure 4 shows the variation of the specific heat versus temperature, we note that this parameter evolves exponentially and its enhancement is proportional to the increase of temperature, but the addition of nanoparticles influences inversely this behaviour by

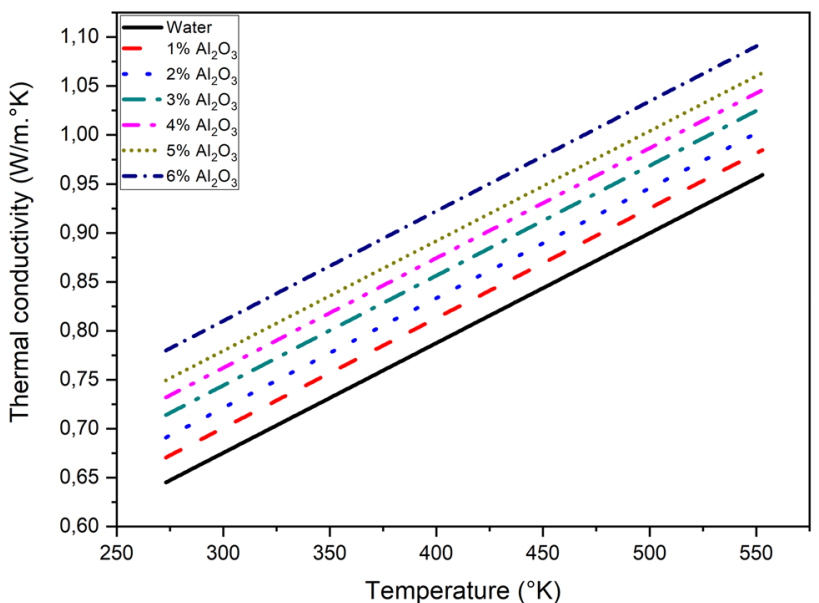

Fig. 3 Evolution of $\mathrm{Al}_{2} \mathrm{O}_{3}$ /water nanofluid thermal conductivity

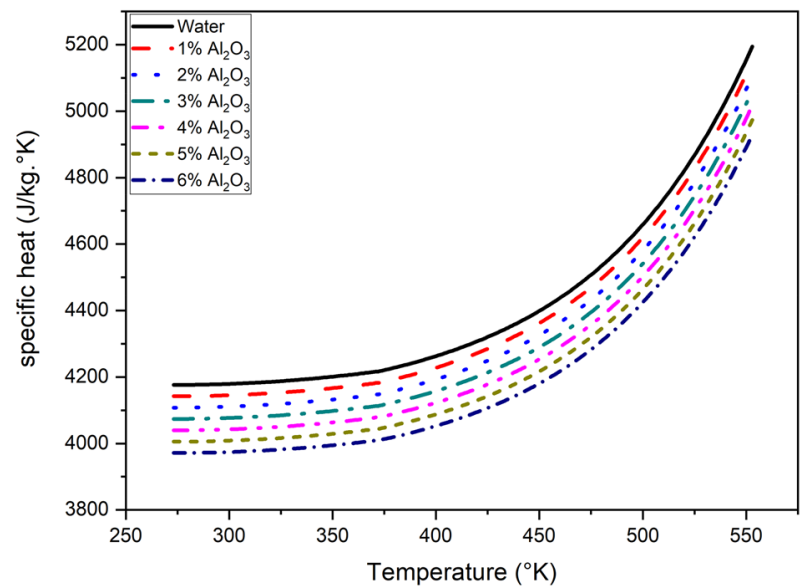

Fig. 4 Specific heat evolutions of $\mathrm{Al}_{2} \mathrm{O}_{3}$ /water nanofluid

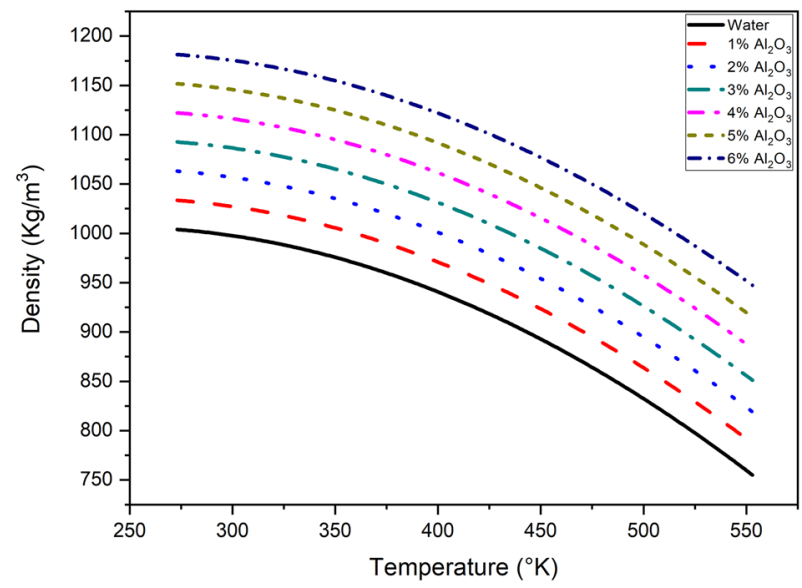

Fig. 5 Evolution of density of $\mathrm{Al}_{2} \mathrm{O}_{3}$ /water nanofluid 
its decrease. Figure 5 , shows that the density decreases by increasing the temperature, while its increase is combined with the addition of the volume fraction.

\section{Computational procedure}

In this part, we will see a set of groups defining the behaviour of the fluids within our heat exchanger, these groups will be the pillars of our investigation and will be one of the elements to fix the axis of simulation. Thus, their determination and introduction in the COMSOL Multiphysics platform will allow us to build a simulation application that will be tested and validated by comparing its results with those of experimental data. In this work, we assume that our system is perfectly insulated, no thermal loss to the outside (adiabatic system), the correlations used for the dimensionless Nusselt number calculation are Mc Adams (Turbulent regime) $\mathrm{Nu}=0.023 \cdot \mathrm{Re}^{0.8} \cdot \mathrm{Pr}^{0.4}$ and Colburn (Laminar regime) $N u=0.023 \cdot R^{0.8} \cdot \operatorname{Pr}^{0.33}$.

To determine the temperature profiles, the effectiveness, the power and the overall heat coefficient in our heat exchanger, it is necessary to calculate some parameters describing the thermal character and the flowing nature.

In the nanofluid, the coefficient of convection heat exchange $h_{N f}$ is given by:

$h_{N f}=\frac{N u \cdot \lambda_{N f}}{D_{h N f}}$

where, the dimensionless Nusselt and Reynolds numbers are determined by, respectively:

$\mathrm{Nu}=0.023 \cdot \operatorname{Re}^{0.8} \cdot \operatorname{Pr}^{0.4}$

and

$R e=\frac{4 \cdot \dot{m}_{N f}}{\mu_{N f} \cdot \pi \cdot D_{h N f}}$

With Prandtl number is defined as:

$\operatorname{Pr}=\frac{C p_{N f} \cdot \mu_{N f}}{\lambda_{N f}}$

Otherwise, the coefficient of heat convective exchange in the lubricant side $h_{\text {lubricant }}$ is obtained by similar equations used in $h_{N f}$, but now Nusselt and Reynolds numbers are determined as:

$N u=0.023 \cdot \operatorname{Re}^{0.8} \cdot \operatorname{Pr}^{0.33}$

and
$R e=\frac{\dot{m}_{\text {lubricant }} \cdot\left(D_{\text {lubricant }}-D_{N f}\right)}{\mu_{\text {lubricant }} \cdot\left(\frac{\pi \cdot D_{\text {lubricant }}{ }^{2}}{4}-\frac{\pi \cdot D_{N f}{ }^{2}}{4}\right)}$

As a result, the overall coefficient of heat exchange is computed by the following equation:

$K=\frac{1}{\frac{1}{h_{N f}}+\frac{1}{h_{\text {lubricant }}}}$

\subsection{Determination of outlet temperatures}

The heat balance between hot fluid (lubricant) and cold fluid ( $\mathrm{Al}_{2} \mathrm{O}_{3}$ /water nanofluid) leads to the calculate of the effectiveness of the heat exchanger, the quantity of heat exchanged by these two fluids as a result of this assessment. Applying the Number of Transfer Units (NTU) Method, we deduce the outlet temperatures from the nanofluid and lubricant. The first step is to perform an efficiency analysis, to quantify the thermal flow rate $q_{t}=\left[\dot{m} C_{p}\right]$, which is given by:

- For hot fluid (Lubricant):

$q_{\text {th }}=\dot{m}_{\text {lubricant }} C p_{\text {lubricant }}$

- For cold fluid $\left(\mathrm{Al}_{2} \mathrm{O}_{3}\right.$ /water nanofluid):

$q_{t c}=\dot{m}_{N f} C p_{N f}$

The effectiveness analysis requires the calculation of the following parameters:

- The heat capacity ratio:

$$
C=\frac{\left[\dot{m} C_{p}\right]_{\min }}{\left[\dot{m} C_{p}\right]_{\max }}=\frac{\left[\dot{m}_{N f} C p_{N f}\right]}{\left[\dot{m}_{\text {lub }} C p_{\text {lub }}\right]}
$$

- The maximum heat transferred between fluids:

$$
Q_{\max }=\left[\dot{m}_{N f} C p_{N f}\right]\left(T_{i, \text { lubricant }}-T_{i, N f}\right)
$$

- The Number of Transfer Units (NTU):

$$
N T U=\frac{K . S}{\left[\dot{m}_{N f} C p_{N f}\right]}
$$

With

$S=2 \pi r L=\pi D_{N f} L$

The effectiveness is a dimensionless quantity between 0 and 1 . In counter-flow configuration this parameter is calculated as: 
$\varepsilon=\frac{1-\exp [-N T U(1-C)]}{1-C \cdot \exp [-N T U(1-C)]}$

Using the following equation:

$Q_{r}=\varepsilon \mid \operatorname{dot}_{\max }$

we calculate the heat transferred between fluids and we determine the output temperatures:

The outlet lubricant temperature is given as follows:

$T_{\text {o,lubricant }}=T_{i, \text { lubricant }}-\frac{Q_{r}}{\dot{m}_{\text {lubricant }} \cdot C p_{\text {lubricant }}}$

And the outlet nanofluid temperature is given by:

$T_{o, N f}=T_{i, N f}+\frac{Q_{r}}{\dot{m}_{N f} \cdot C p_{N f}}$

Consequently, it is possible to calculate the heat exchanger power with the following formula:

$P=K . S . L M D T$

With the LMTD (Logarithmic Mean Temperature Difference) is defined as:

$L M T D=\frac{\left(T_{o, \text { lubricant }}-T_{i, N f}\right)-\left(T_{i, \text { lubricant }}-T_{o, N f}\right)}{\ln \left(\frac{T_{o, \text { lubricant }}-T_{i, N f}}{T_{i, \text { lubricant }}-T_{o, N f}}\right)}$

After introducing all these parameters in the COMSOL Multiphysics application, A validation simulation carried out. Table 3 shows the results for the same conditions as the actual case of the installation, using water as a cooling fluid. A good agreement is then found between the simulation results and the experimental data. Thus, the model will be used to simulate and find solutions to improve the thermal performance of the device.

\section{Mesh implementation}

Any solution of problems by the finite element method must begin with a creation of the mesh that represents the field of

Table 3 Comparison of the experimental data and the results of the simulation for water as a cooling

\begin{tabular}{lll}
\hline & Experimental data & Simulation results \\
\hline$T_{i, \text { lubricant }}$ & $360^{\circ} \mathrm{K}$ & $360^{\circ} \mathrm{K}$ \\
$T_{o, \text { lubricant }}$ & $315^{\circ} \mathrm{K}$ & $315^{\circ} \mathrm{K}$ \\
$T_{i, B f}($ Water $)$ & $300^{\circ} \mathrm{K}$ & $300^{\circ} \mathrm{K}$ \\
$T_{o, B f}($ Water $)$ & $316.7^{\circ} \mathrm{K}$ & $316.3^{\circ} \mathrm{K}$ \\
LMTD & $27.67^{\circ} \mathrm{K}$ & $27.60^{\circ} \mathrm{K}$ \\
Effectiveness & 0.420 & 0.418 \\
Power & $6321(\mathrm{~W})$ & $6319(\mathrm{~W})$ \\
\hline
\end{tabular}

our study. This step is often delicate because the quality of the finite element approximation depends strongly on the mesh structure. On the other hand, the mesh size should not be excessively tightened because the finer mesh size is more expensive on the calculation time. The meshing strategy then becomes delicate; it is a matter of refining the mesh in the significant areas (contact zones in this case) and applying a coarser mesh elsewhere. The COMSOL Multiphysics software allows us to visualize the mesh quality according to a purely geometric, triangular, diamond, or quadratic criterion. In the case of our configuration, we used a quadratic mesh with a tightening at the edges. Figure 6 shows a symmetrical section of the double-pipes of our heat exchanger, it is seen that we have used tightening at the level of the zones where we have the birth of different thermal phenomena, for example at the level of the inner tube contact zone with the outer tube fluid, we have the thermal conduction of the inner tube as well as the thermal convection at the level of the inner and outer tubes and therefore the thinness of the mesh in this zone is important to give all possible information for our calculation process.

\section{Simulation results and discussions}

In what follows and after validation of the simulation model, particular attention has been paid to the solution that can affect an increase in the performance of the heat exchanger. We opted for an evaluation of the heat exchanger performances using $\mathrm{Al}_{2} \mathrm{O}_{3}$ /water nanofluid for different concentrations. The study is focused on the effect of the nanofluids volume fractions increase on the heat performance of the exchanger, as

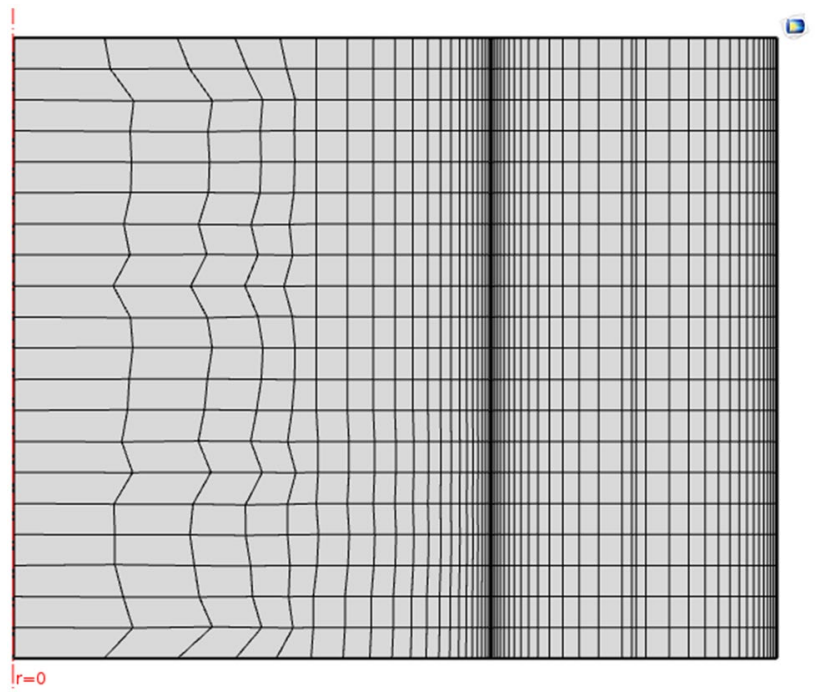

Fig. 6 Representation of the mesh used 


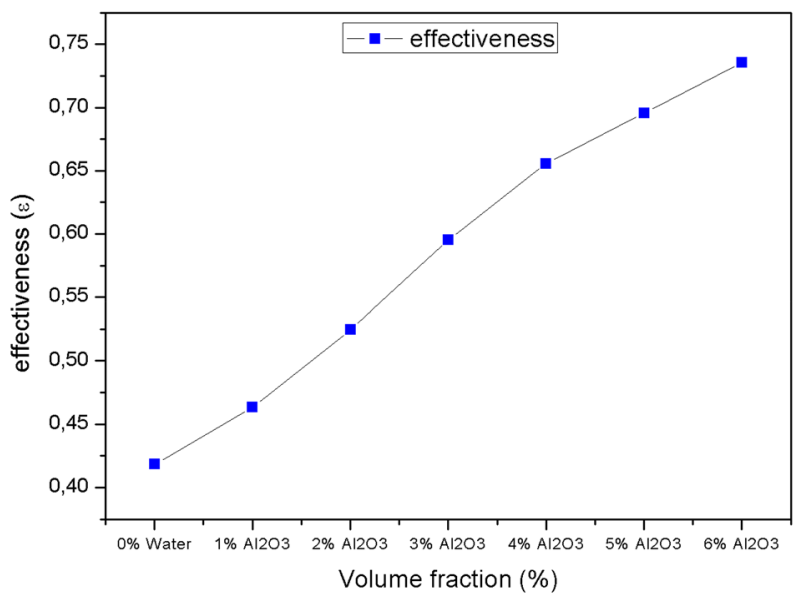

Fig. 7 Evolution of the effectiveness of the heat exchanger

well as its influence on the power exchanged between the two fluids, the efficiency and the inlet and outlet temperature pinch of the exchanger. By analysing the results obtained from numerical simulations made on the application built on the COMSOL Multiphysics platform, various findings were made for the process parameters. We observed an increase in the efficiency of the exchanger that is proportional to the increase in the volume fraction of the alumina-based nanofluid $\left(\mathrm{Al}_{2} \mathrm{O}_{3}\right.$ /water nanofluid). It is noted that an increase of $1 \%$ of the volume fraction generates an increase of $10.80 \%$ in the exchanger efficiency (Fig. 7). Although the increase in the volume fraction of the nanofluid is an important factor that affects thermal properties of our configuration, we see an increase of the global exchange coefficient as well as the number of transfer units (NTU), these increases are respectively $17.62 \%$ and $3.238 \%$ (Figs. 8 and 9) for $1 \%$ volume fraction addition. As far as the power of the exchanger is concerned, it has been deduced that the addition of the suspension fraction of nanoparticles favours the increase of the heat exchanger power, this is quantified by an increase of $1.473 \%$ for a proportion of $1 \%$ of volume fraction (Fig. 10). Moreover, the analysis of the outlet temperatures of the lubricant and the nanofluid, which describe the profile of the inlet and outlet pinch of our configuration, shows that the use of the nanofluid with different volume fractions leads to a reduction of the pinches input and output. This is explained by the drop in the Logarithmic Mean Temperature Difference (LMTD). This suggests that nanofluids absorb more calories than basic fluids generating a drop of the order of $3.015 \%$ for an addition of $1 \%$ volume fraction of $\mathrm{Al}_{2} \mathrm{O}_{3}$ /water nanofluid Figs. 11 and 12 .

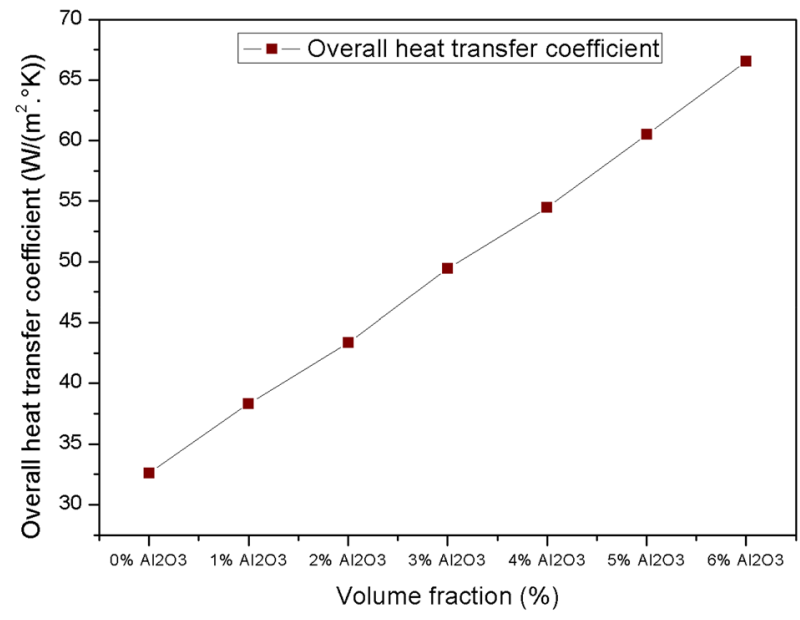

Fig. 8 Overall heat transfer coefficient for each volume fraction

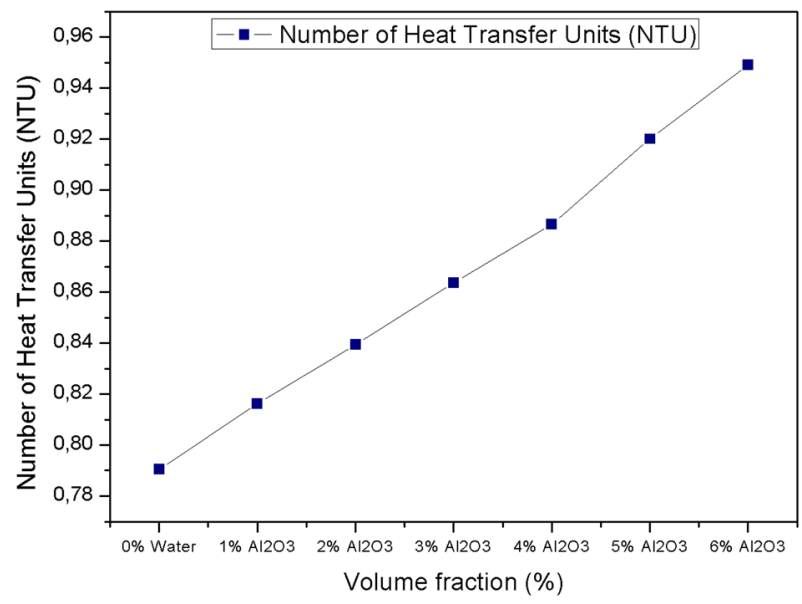

Fig. 9 The appearance of the NTU corresponding to the increase of fractions of nanofluids

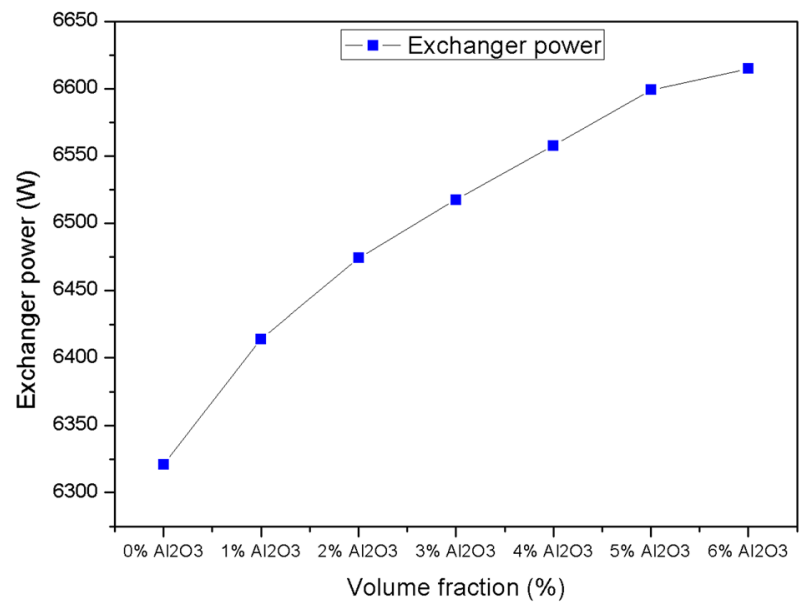

Fig. 10 The evolution of the exchanger power with respect to the increase of the volume fraction 


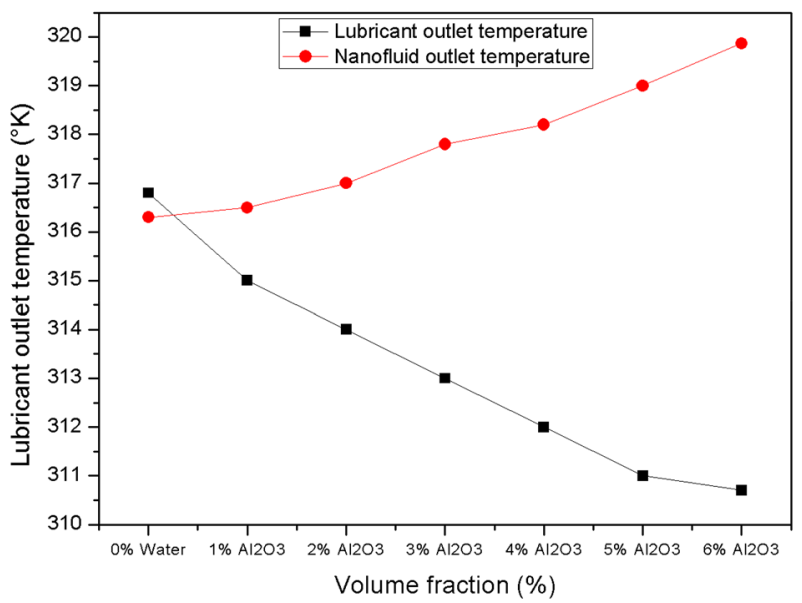

Fig. 11 The character of the outlet temperatures on the lubricant and cooling fluid sides

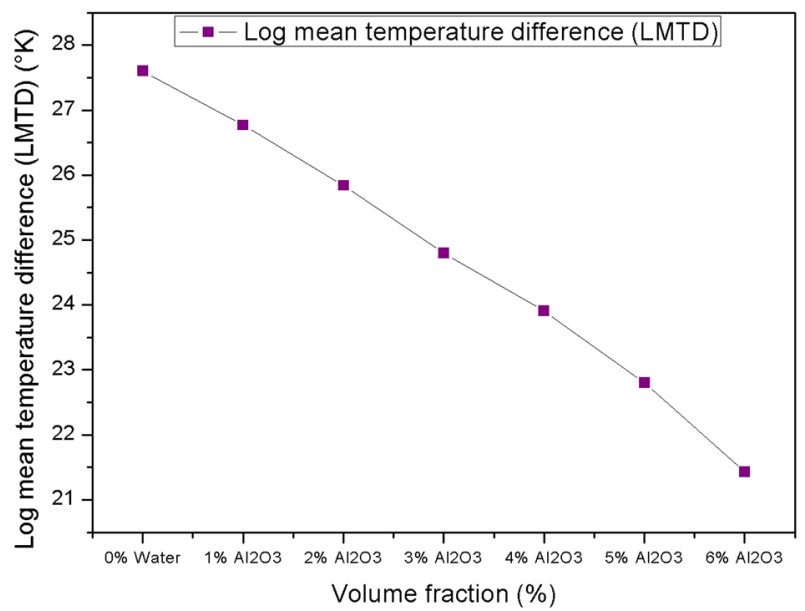

Fig. 12 Profile of the LMTD for an increase in the volume fraction of nanofluids

\section{Conclusion}

In this work, the thermal performance of a double-pipe heat exchanger configuration providing cooling of lubricating oil in a thermoelectric power plant was investigated. The use of an alumina-based nanofluid as a coolant was proposed as an alternative to improve the efficiency of this process. Heat transfer, efficiency and power of exchanger and temperature variation were evaluated using numerical simulations through an application developed on COMSOL Multiphysics environment. The influence of the increase in the volume fraction of nanofluids was studied, leading to the following ideas. Firstly, the addition of nanoparticles has more effects on the overall and the convective heat transfer coefficients, it was observed that the addition of
$1 \%$ volume fraction leads to an increase of $17.62 \%$ in the overall heat transfer coefficient. It is also observed that the Number of Transfer Units has a progressive character according to the addition of nanoparticles, which is quantified by a gain of $3.24 \%$ on a $1 \%$ of the volume fraction increase. This study also looked at the efficiency of the exchanger, in this case, a $10.80 \%$ increase in exchanger efficiency by the addition of a $1 \%$ volume fraction. This increase affects also the exchanger power, it is assumed that a $1 \%$ volume fraction increases the power by $1.473 \%$. In all the studied cases, a regression of the temperature inlet and outlet pinches was observed, which means the interest of the nanofluid in the sub-cooling of the lubricant compared to the base fluids. This study will give a continuation of work that will be the subject of the same analysis for other exchanger configurations, namely shell and tube and fate plates and to make a comparative study on the dimensions of these types of exchangers, to choose a solution that includes efficiency, power with less space.

Acknowledgements The authors would like to thank Prof. M. Zeroual for his useful discussions, his constructive comments and the time he took to revise our paper.

Funding This study was not funded.

\section{Compliance with ethical standards}

Conflict of interest On behalf of all authors, the corresponding author states that there is no conflict of interest.

Open Access This article is licensed under a Creative Commons Attribution 4.0 International License, which permits use, sharing, adaptation, distribution and reproduction in any medium or format, as long as you give appropriate credit to the original author(s) and the source, provide a link to the Creative Commons licence, and indicate if changes were made. The images or other third party material in this article are included in the article's Creative Commons licence, unless indicated otherwise in a credit line to the material. If material is not included in the article's Creative Commons licence and your intended use is not permitted by statutory regulation or exceeds the permitted use, you will need to obtain permission directly from the copyright holder. To view a copy of this licence, visit http://creativecommons .org/licenses/by/4.0/.

\section{References}

1. Mahian O, Kianifar A, Kalogirou SA, Pop I, Wongwises S (2013) A review of the applications of nanofluids in solar energy. Int J Heat Mass Transf 57(2):582-594

2. S. U.S. Choi and J. Eastman (1995) Enhancing thermal conductivity of fluids with nanoparticles. 66

3. Mir S et al (2020) A comprehensive study of two-phase flow and heat transfer of water/Ag nanofluid in an elliptical curved minichannel. Chinese J Chem Eng 28(2):383-402

4. Bahiraei M, Jamshidmofid M, Amani M, Barzegarian R (2018) Investigating exergy destruction and entropy generation for 
flow of a new nanofluid containing graphene-silver nanocomposite in a micro heat exchanger considering viscous dissipation. Powder Technol 336(2017):298-310

5. Bahiraei M, Ahmadi AA (2018) Thermohydraulic performance analysis of a spiral heat exchanger operated with water-alumina nanofluid: Effects of geometry and adding nanoparticles. Energy Convers Manag 170(May):62-72

6. Bahiraei M, Kiani Salmi H, Safaei MR (2018) Effect of employing a new biological nanofluid containing functionalized graphene nanoplatelets on thermal and hydraulic characteristics of a spiral heat exchanger. Energy Convers. Manag. 180:72-82

7. Sözen A, Khanları A, Çiftçi E (2019) Heat transfer enhancement of plate heat exchanger utilizing kaolin-including working fluid. Proc Inst Mech Eng Part A J Power Energy. 233(5):626-634

8. Sözen A (2019) Experimental and numerical investigation of heat transfer enhancement in a plate heat exchanger for performance improvement. Int J Renew Energy Dev 8(1):27-32

9. Bahmani MH et al (2018) Investigation of turbulent heat transfer and nanofluid flow in a double pipe heat exchanger. Adv Powder Technol 29(2):273-282

10. Goodarzi M et al (2016) Investigation of heat transfer performance and friction factor of a counter-flow double-pipe heat exchanger using nitrogen-doped, graphene-based nanofluids. Int Commun Heat Mass Transf 76:16-23

11. Akbari OA et al (2016) Investigation of rib's height effect on heat transfer and flow parameters of laminar water-AI2O3 nanofluid in a rib-microchannel. Appl Math Comput 290:135-153

12. Bahiraei $M$, Rahmani $R$, Yaghoobi $A$, Khodabandeh E, Mashayekhi R, Amani M (2018) Recent research contributions concerning use of nanofluids in heat exchangers: A critical review. Appl Therm Eng 133:137-159

13. Omidi M, Farhadi M, Jafari M (2017) A comprehensive review on double pipe heat exchangers. Appl Therm Eng 110:1075-1090

14. Kumar V, Tiwari AK, Ghosh SK (2015) Application of nanofluids in plate heat exchanger: A review. Energy Convers Manag 105:1017-1036

15. Huminic G, Huminic A (2012) Application of nanofluids in heat exchangers: A review. Renew Sustain Energy Rev 16(8):5625-5638

16. Giwa SO, Sharifpur M, Goodarzi M, Alsulami H, Meyer JP (2020) Influence of base fluid, temperature and concentration on the thermophysical properties of hybrid nanofluids of alumina-ferrofluid: experimental data, modeling through enhanced ANN, ANFIS and curve fitting. J. Therm. Anal. Calorim. 56:0123456789

17. Gürbüz EY, Variyenli HI, Sözen A, Khanlari A, Ökten M (2020) Experimental and numerical analysis on using CuO-Al2O3/ water hybrid nanofluid in a U-type tubular heat exchanger. Int. J. Numer, Methods Heat Fluid Flow

18. Ghalambaz M, Mehryan SAM, Hajjar A, Veismoradi A (2020) Unsteady natural convection flow of a suspension comprising Nano-Encapsulated Phase Change Materials (NEPCMs) in a porous medium. Adv Powder Technol 31(3):954-966

19. Ho CJ, Liu YC, Ghalambaz M, Yan WM (2020) Forced convection heat transfer of Nano-Encapsulated Phase Change Material (NEPCM) suspension in a mini-channel heatsink. Int J Heat Mass Transf. 23:155

20. Khanafer K, Vafai K, Lightstone M (2003) Buoyancy-driven heat transfer enhancement in a two-dimensional enclosure utilizing nanofluids. Int J Heat Mass Transf 46(19):3639-3653

21. Aghayari R, Maddah $H$, Zarei M, Dehghani M, Kaskari Mahalle SG (2014) Heat Transfer of Nanofluid in a Double Pipe Heat Exchanger. Int Sch Res Not. 20:1-7

22. Pak BC, Cho YI (1998) Hydrodynamic and heat transfer study of dispersed fluids with submicron metallic oxide particles. Exp Heat Transf 11(2):151-170

23. Sarviya RM, Fuskele V (2017) Review on Thermal Conductivity of Nanofluids. Mater Today Proc 4(2):4022-4031

24. Wasp EJ, Kenny JP, Gandhi RL (1977) Solid-liquid flow: slurry pipeline transportation [Pumps, valves, mechanical equipment, economics]. Ser. Bulk Mater. Handl. 1(4):88

25. Bashirnezhad K et al (2016) Viscosity of nanofluids: A review of recent experimental studies. Int Commun Heat Mass Transf 73:114-123

26. Bachir G (2010) Contribution à l'étude de la convection naturelle dans les nanofluides en configuration de Rayleigh-Bénard. Université de Toulouse, Université Toulouse III-Paul Sabatier

27. V. Bianco, O. Manca, S. Nardini and K. Vafai (2015) Heat transfer enhancement with nanofluids.

28. Vajjha RS, Das DK (2009) Specific Heat Measurement of Three Nanofluids and Development of New Correlations. J Heat Transfer 131(7):071601

29. Li CH, Peterson GP (2006) Experimental investigation of temperature and volume fraction variations on the effective thermal conductivity of nanoparticle suspensions (nanofluids). J Appl Phys. 99(8):31

30. Mahbubul IM, Saidur R, Amalina MA (2012) Latest developments on the viscosity of nanofluids. Int J Heat Mass Transf 55(4):874-885

Publisher's Note Springer Nature remains neutral with regard to jurisdictional claims in published maps and institutional affiliations. 